\title{
Coordination of dual setting overcurrent relays in microgrid with optimally determined relay characteristics for dual operating modes
}

\author{
Raghvendra Tiwari ${ }^{*}$, Ravindra Kumar Singh and Niraj Kumar Choudhary
}

\begin{abstract}
Fault current magnitude in a microgrid depends upon its mode of operation, namely, grid-connected mode or islanded mode. Depending on the type of fault in a given mode, separate protection schemes are generally employed. With the change in microgrid operating mode, the protection scheme needs to be modified which is uneconomical and time inefficient. In this paper, a novel optimal protection coordination scheme is proposed, one which enables a common optimal relay setting which is valid in both operating modes of the microgrid. In this context, a common optimal protection scheme is introduced for dual setting directional overcurrent relays (DOCRs) using a combination of various standard relay characteristics. Along with the two variables, i.e., time multiplier setting (TMS) and plug setting (PS) for conventional directional overcurrent relay, dual setting DOCRs are augmented with a third variable of relay characteristics identifier $(\mathrm{RCl})$, which is responsible for selecting optimal relay characteristics from the standard relay characteristics according to the IEC-60255 standard. The relay coordination problem is formulated as a mixed-integer nonlinear programming (MINLP) problem, and the settings of relays are optimally determined using the genetic algorithm (GA) and the grey wolf optimization (GWO) algorithm. To validate the superiority of the proposed protection scheme, the distribution parts of the IEEE-14 and IEEE-30 bus benchmark systems are considered.
\end{abstract}

Keywords: Plug setting, Time multiplier setting, Protection coordination, Overcurrent relay, Coordination time interval

\section{Introduction}

Relay coordination is the operation of protective relays in a proper sequence when a fault occurs. Depending upon the fault location in a network, primary and backup relay pairs (RP) are identified. For proper relay coordination, the primary relay must operate before the backup relay, and there must be a time gap between the primary and backup relay operating times, known as the coordination time interval $(C T I)$ which depends on the type of relays. The CTI is within the range of $0.3-0.6 \mathrm{~s}$ for electromechanical relays, while for microprocessor-based relays it ranges between 0.2 and $0.5 \mathrm{~s}$ [1]. The existing operating time gap between the primary and backup relays, known

${ }^{*}$ Correspondence: raghvendra@mnnit.ac.in

Electrical Engineering Department, MNNIT, Allahabad, Payagraj, UP, India as measured coordination time interval $(M C T)$ must be greater than or equal to CTI to ensure proper coordination among the relays.

A relay coordination scheme has two types of independent variables, namely $T M S$ and $P S$. Depending on these decision variables, the coordination scheme is formulated as a linear, nonlinear, or MINLP programming problems [2]. In linear programming, only TMS is treated as a decision variable, while $P S$ is fixed. Using linear programming (LP) techniques, the optimal value of TMS is obtained by root tree optimization (RTO) [3], improved firefly algorithm (IFA) [4], genetic algorithm (GA) [5], improved harmony search algorithm (IHSA) [6], etc. In nonlinear programming techniques, TMS and $P S$ are both taken as continuous or discrete decision variables. For electromechanical relays, TMS is continuous, and 
$P S$ is taken as a discrete variable whereas, for microprocessor-based relays, both TMS and PS are considered as continuous variables. Using nonlinear programming, the optimal values of TMS and PS are obtained by the modified firefly algorithm (MFA) [7], differential evolution (DE) [8], gravitational search algorithm (GSA) [9], random search technique (RST) [10], teaching learning based optimization (TLBO) [11], etc. To overcome the problem of trapping in local minima, some hybrid techniques consisting of two different optimization techniques, such as gravitational search algorithm-sequential quadratic programming (GSA-SQP) [12], DE-LP [13], biogeography-based optimization-linear programming (BBO-LP) [14], etc. have also been implemented to obtain the optimal values of TMS and PS. In contrast, for the MINLP technique [15], TMS and PS are considered continuous and discrete, respectively. To increase the flexibility in the coordination scheme, relay characteristic coefficients $(\alpha$ and $\beta$ ) have been introduced as another decision variable. Thus, each relay is associated with four decision variables, i.e., TMS, $P S, \alpha$ and $\beta$, to further reduce the total relay operating time as compared to fixed relay characteristics [16].

Using the above-mentioned techniques, several coordination schemes have been proposed for conventional and dual setting DOCR. Conventional DOCR operates for the forward direction of the fault current, and hence there exists a single setting, used by DOCR for both primary and backup operations. Whereas, dual setting DOCR can operate independently for both forward and reverse directions, based upon which two different relay settings $\left(T M S_{\text {fow }}, P S_{\text {fow }}\right.$, and $\left.T M S_{\text {rev }}, P S_{\text {rev }}\right)$, one for each direction, are identified. For the forward direction, the relay will act as the primary, and for the reverse direction, the same relay acts as backup protection in both operating modes of the microgrid. [17]

The fault current characteristics of inverter interface distribution generator (IIDGs) are completely different from those of the conventional rotating synchronous machine-based DGs (SBDGs). The fault current contribution of SBDGs are 4-5 times that of the rated current, whereas, due to the limitation of inverter thermal overload capability, the fault current contribution of IIDGs is limited typically to about 1.2-2 times the rated current [18]. Therefore, overcurrent protection schemes may not be significant in the islanded mode of operation consisting of only IIDGs. However, in the presence of multiple highly penetrated IIDGs along with SBDG, the total fault current contribution can still be significant for the implementation of the overcurrent protection schemes. Because of the fault current variation in grid-connected and islanded modes of the microgrid, two different relay settings are assigned. To obtain a common relay setting for both operating modes, the fault current magnitude must be maintained approximately equal in each mode. To achieve this, a series connected, fault current limiter (FCL) is used for reducing the fault current magnitude in the grid-connected mode during the fault period [19]. However, with the inclusion of an extra device, the protection scheme becomes costly and complicated [20]. To overcome this, a common optimum protection scheme using conventional DOCR for both operating modes of microgrid is proposed in [21], where the combination of optimally selected standard relay characteristics is used. To further improve the performance in terms of the total relay operating time, dual setting DOCR is considered in place of conventional DOCR in this paper, and the common setting is optimally determined for both operating modes of the microgrid. The novelty of this work lies in identifying common settings for dual setting relays in both operating modes without using any external element or communication system.

The protection scheme for the relay coordination problem formulated in this paper is an MINLP because of the involvement of the third decision variable $R C I$. The proposed protection scheme is tested on the 7-bus and 18-bus microgrid systems. To show the effectiveness of dual setting DOCR, its performance is compared with the results obtained by conventional DOCRs [21]. The remainder of the paper is divided into five sections as follows. Section 2 describes problem formulation using dual setting DOCRs, and the solution method is defined in Sect. 3. Section 4 provides a brief discussion of the test system and results, while validation of the proposed protection scheme on a larger microgrid system is presented in Sect. 5. Finally, the conclusion is given in Sect. 6.

\section{Relay coordination problem formulation in a microgrid}

The operating time of overcurrent relay depends on its time-current characteristics, classified according to IEC-60255 standard as normal inverse (NI), very inverse (VI), and extremely inverse (EI), as shown in Fig. 1. Each relay characteristic is identified considering the respective characteristic coefficients as shown in Table 1. From Fig. 1, it can be seen that, for a fixed fault current value, the relay operating time is reduced as the relay characteristics change from NI to EI. The relay characteristics shown in Fig. 1 can be derived for different values of TMS and PS using (2) and (3). The objective of the proposed work is to find optimum relay settings and reduce the overall operating time of dual setting DOCR for both operating modes of the microgrid.

The objective function (OF) for relay coordination is formulated as the summation of all primary relay operating 


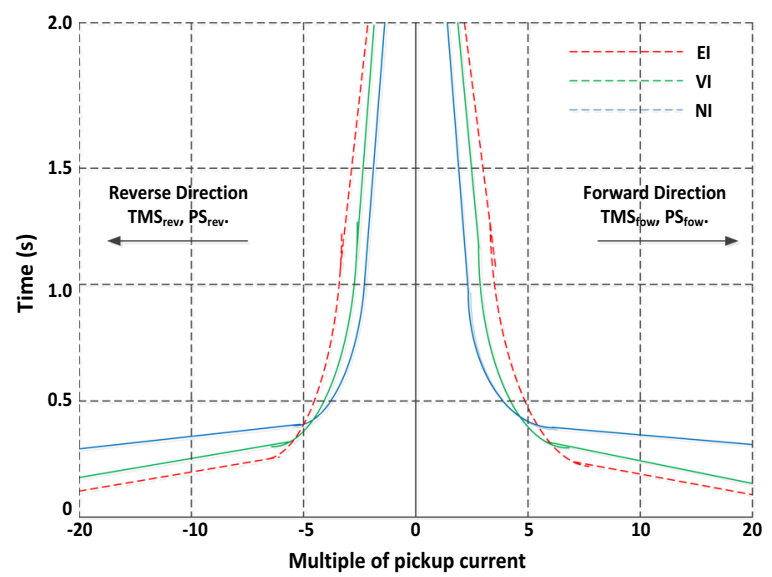

Fig. 1 Time-current characteristics of a dual setting DOCR

Table 1 Overcurrent relay characteristics coefficient, according to IEC-60255 std

\begin{tabular}{llll}
\hline Characteristic curve of relay & $\boldsymbol{a}$ & $\boldsymbol{\beta}$ & $\begin{array}{l}\text { Relay } \\
\text { characteristics } \\
\text { identifier (RCI) }\end{array}$ \\
\hline Very inverse (VI) & 13.5 & 1 & 1 \\
Extremely inverse (EI) & 80 & 2 & 2 \\
Normal inverse (NI) & 0.14 & 0.02 & 3 \\
\hline
\end{tabular}

times for different fault locations shown in (1) and the required constraints to fulfill the objective of the relay coordination problem are given from (4) to (7).

$$
O F=\min \sum_{i=1}^{n} t_{\text {op_fow }}^{i}
$$

where

$$
\begin{aligned}
& t_{\text {op_fow }}^{i}=\frac{\alpha * T M S_{\text {fow }}}{\left\{\frac{I_{f}}{P S_{\text {fow }} * C T R}\right\}^{\beta}-1} \\
& t_{\text {op_rev }}=\frac{\alpha * T M S_{\text {rev }}}{\left\{\frac{I_{f}}{P S_{\text {rev }} * C T R}\right\}^{\beta}-1} \\
& t_{\text {op_rev }}-t_{\text {op_fow }} \geq C T I \\
& t_{\text {op_min }} \leq t_{\text {op_fow }} \leq t_{\text {op_ }} \max \\
& T M S_{\min } \leq T M S_{\text {fow }}, T M S_{\text {rev }} \leq T M S_{\max }
\end{aligned}
$$

$$
P S_{\min } \leq P S_{\text {fow }}, P S_{\text {rev }} \leq P S_{\max }
$$

In (1), $t_{\text {op fow }}^{i}$ is the operating time of the $i$ th relay in the forward direction, and $n$ is the number of primary relays for different fault locations. The relay operating times for forward and reverse directions of fault current are $t_{\text {op fow }}$ and $t_{\text {op_rev, }}$ respectively, as given in (2) and (3). The relay characteristic coefficients $\alpha$ and $\beta$ are selected as per IEC60255 standard. $T M S_{\text {fow }}$ and $T M S_{\text {rev }}$ are the time multiplier setting and $P S_{\text {fow }}$ and $P S_{\text {rev }}$ are the plug setting of relays operating in forward and reverse directions respectively. In (4), CTI is the coordination time interval, and its minimum value is $0.2 \mathrm{~s}$. The maximum and minimum operating time of relays $\left(t_{\text {op_max }}\right.$ and $\left.t_{\text {op_min }}\right)$ are $4.0 \mathrm{~s}$ and $0.1 \mathrm{~s}$, respectively. Different kind of transients may exist in the power system for a time period of less than one microsecond to several milliseconds. In order to tackle all the transients in the system, the minimum relay operating time $(0.1 \mathrm{~s})$ is also considered as a constraint to establish the overcurrent relay coordination. Therefore, all transients vanish before the operation of the primary relay. The lower and upper bound of TMS $\left(T M S_{\min }\right.$ and $\left.T M S_{\max }\right)$ and PS $\left(P S_{\min }\right.$ and $\left.P S_{\max }\right)$ are $0.1,1.1,0.5,2.0$ respectively.

\section{Solution method for the relay coordination problem}

The optimal coordination among the dual setting DOCRs can be achieved by obtaining the optimum values of relay settings, i.e., $T M S_{\text {fow }} T M S_{\text {rev }} P S_{\text {fow, }}$ and $P S_{\text {rev }}$, along with the optimal selection of relay characteristics $R C I$. The optimal values of all decision variables must be selected to reduce the total relay operating time without any violation of constraints. Thus, each relay is associated with twice the number of variables used in conventional DOCR. For the forward direction of fault current, the relay is associated with the forward settings $\left(T M S_{\text {fow }} P S_{\text {fow }}\right.$ and $\left.R C I\right)$ and for the reverse direction the same relay is associated with reverse settings $\left(T M S_{\text {rev }} P S_{\text {rev }}\right.$ and $\left.R C I\right)$. In this paper GA and GWO are used to obtain the values of all decision variables. The structure of the chromosome used in GA for dual setting DOCR is shown in Fig. 2.

The proposed protection method using dual setting DOCR for both operating modes of the microgrid is shown in Fig. 3. In the proposed protection scheme, the first step is to identify the operating mode of the microgrid, and then the three-phase midpoint fault current is measured at each line using short circuit analysis. The relay pairs (primary

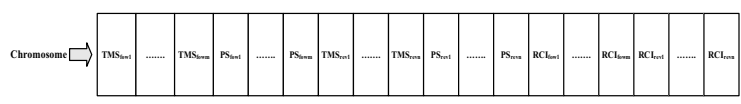

Fig. 2 Structure of chromosome in GA technique 


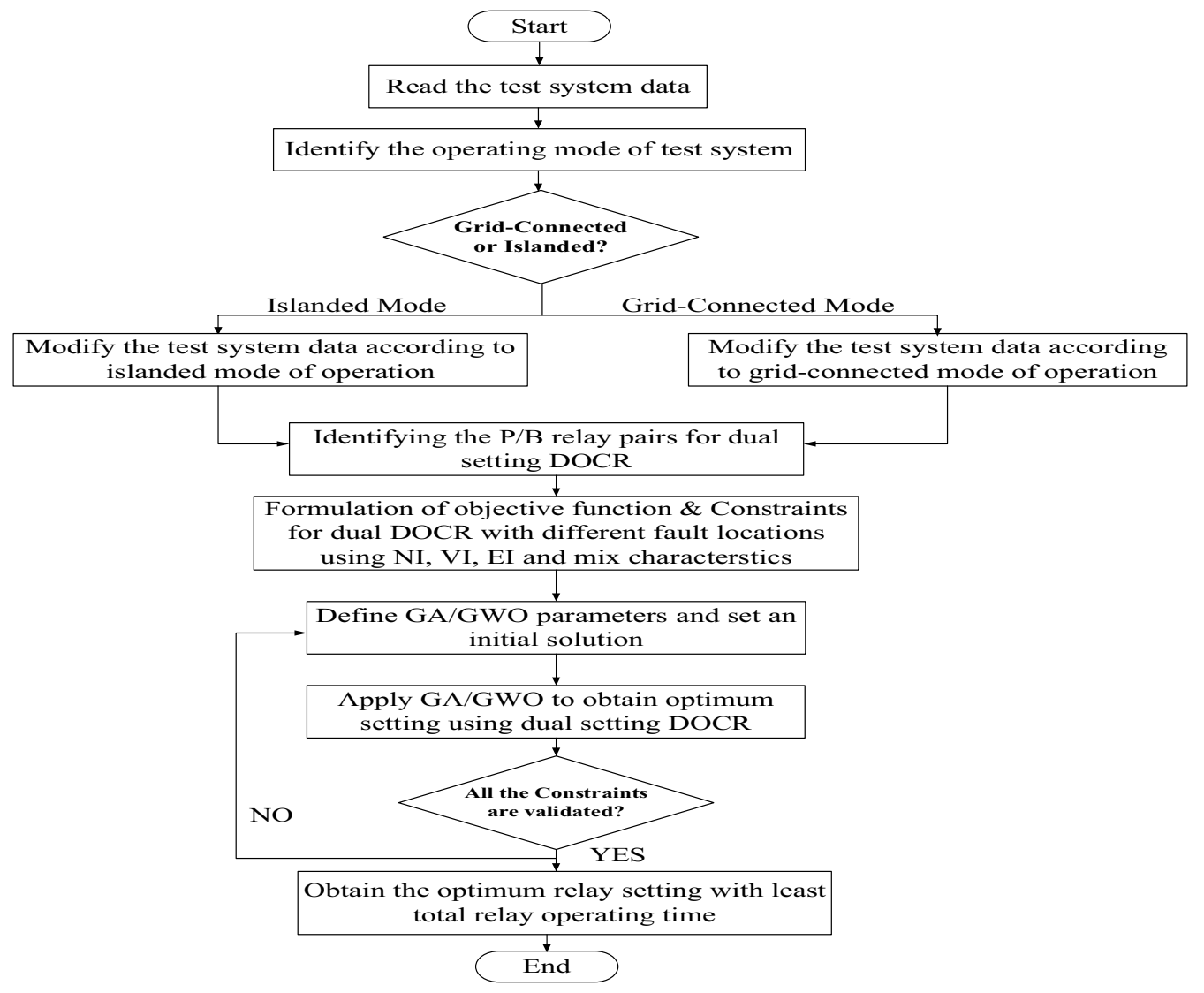

Fig. 3 Proposed protection method to determine optimal relay setting in grid connected and islanded operating mode

and backup) for the different fault locations are identified in both operating modes. Furthermore, the summation of the operating times of all primary relays is taken as an objective function, and all the constraints related to $C T I$ as well as minimum and maximum relay operating times are formulated. After the determination of GA/GWO parameters, the optimum settings of relays are obtained. If the obtained values satisfy all the constraints for both operating modes, they are considered as the final optimal relay settings. However, in the case where there is any violation of constraints, the values of GA/GWO parameters are updated and the process continues until the final optimal relay setting is obtained without any violation of relay constraints.

\section{Test system description and results}

In this paper, for both test systems considered (distribution parts of the IEEE-14 and IEEE-30 bus test systems), multiple IIDGs are used along with one SBDG and a utility grid. Therefore, the total fault current in grid connected mode is shared by all the considered active sources of IIDGs, SBDG and the utility grid. In the islanded mode of operation, the total fault current is shared by multiple IIDGs and the SBDG. The distribution part of the IEEE-14 bus system (7-bus microgrid system), as shown in Fig. 4, has two inverter-based DGs (IBDGs) each rated at $20 \mathrm{MVA}$, connected at buses $\mathrm{B} 2$ and $\mathrm{B} 7$, and one synchronous generator (SG) of 50 MVA at bus B1. The 7-bus microgrid system is connected with the subtransmission network through buses B3 and B6 each having 60 MVA generation capacity. Buses B1, B2, B3, and B6 have a maximum short circuit capacity of $250 \mathrm{MVA}$, 80 MVA, 300 MVA, and 300 MVA, respectively. All other specifications of the test system can be obtained from [22]. The 7-bus microgrid test system consists of 8 lines, which are protected by 16 dual setting DOCRs placed at both ends of the lines. The CT ratios (CTR) used for dual setting DOCRs are given in Table 2. The fault current magnitudes through each relay coil for different fault locations in both operating modes of the microgrid are shown in Table 3. For eight different fault locations (L1, L2, L8), there are twenty-two relay pairs (RP1-RP22). For relay pair RP1, R1 and R3 will act as the primary and backup dual setting DOCR, respectively. The fault current via the primary and backup relay coils in grid-connected and islanded operating modes are 12.075A (R1), 3.19A (R3), 9.03A (R1), and 0.64A (R3), respectively. 


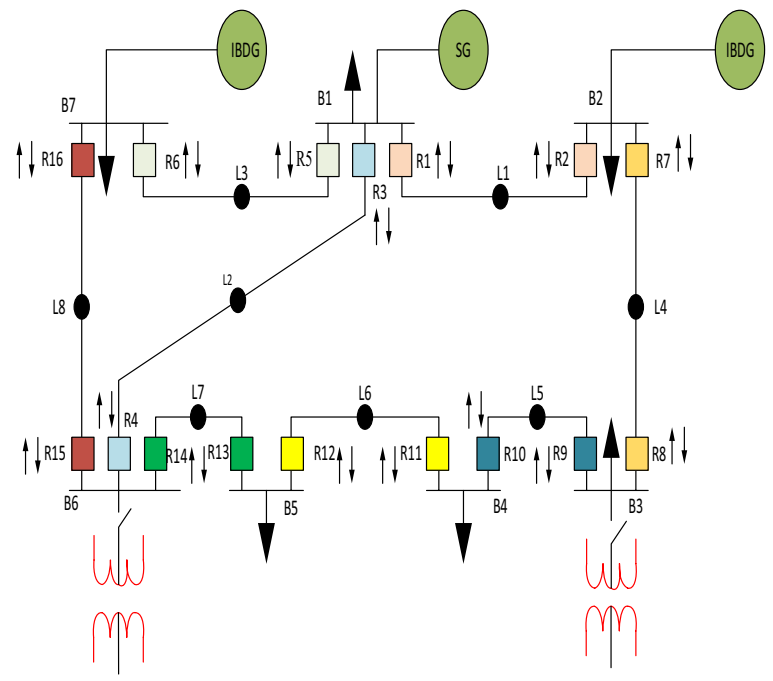

Fig. 4 Distribution part of IEEE-14 bus test system with dual setting DOCR

Table 2 CT ratios of DOCR for 7-bus microgrid system

\begin{tabular}{lc}
\hline Relay & CT ratio \\
\hline 1 & $2000 / 5$ \\
2 & $1000 / 5$ \\
3 & $3000 / 5$ \\
4 & $2000 / 5$ \\
5 & $1600 / 5$ \\
6 & $1000 / 5$ \\
7 & $2500 / 5$ \\
8 & $1600 / 5$ \\
9 & $2500 / 5$ \\
10 & $1200 / 5$ \\
11 & $1200 / 5$ \\
12 & $2500 / 5$ \\
13 & $800 / 5$ \\
14 & $3000 / 5$ \\
15 & $1600 / 5$ \\
16 & $1600 / 5$ \\
\hline
\end{tabular}

It can be seen from the short circuit analysis that the fault current magnitude in grid-connected mode is higher than in the islanded mode of operation. Consequently, it is possible that DOCRs with NI relay characteristics may take a long time to operate. This is not desirable as it may lead to mis-coordination of relay pairs, potentially resulting in a larger portion of the system being isolated. To avoid this situation, relay characteristic curves have been optimally selected by including a third optimization variable known as a relay characteristics identifier (RCI). Besides this, the fault current magnitude in the forward direction is higher than the reverse direction, which justifies the need of dual setting relays.

\subsection{Optimum relay setting in grid-connected mode}

The settings of the optimal dual setting DOCR obtained by GA in the grid-connected mode of operation, using NI, VI, EI and mixed relay characteristics, are shown in Table 4. The total operating times of all dual setting DOCRs with NI and VI characteristics are found to be $3.3877 \mathrm{~s}$ and $1.6825 \mathrm{~s}$, respectively. From the results, it can be seen that by using VI characteristics the overall relay operating time can be reduced by up to $50.33 \%$ when compared to NI characteristics. From the obtained optimal settings, it can be seen that for NI characteristics, the operating time of R1 in RP1 is $0.2146 \mathrm{~s}$ for the forward direction, whereas for the reverse direction the operating time of R1 in RP4 is $2.049 \mathrm{~s}$. Thus, the relay operating time for the forward direction of fault current is lower than the reverse direction. This statement is valid for all the dual setting DOCRs with NI, VI, EI, and mixed characteristics in grid-connected mode. Similarly, the results obtained using EI relay characteristics and a combination of optimally selected relay characteristics (mixed-characteristics) in grid-connected mode show that the total operating times of dual setting DOCRs with EI and mixed characteristics are $1.6124 \mathrm{~s}$ and $1.6065 \mathrm{~s}$, respectively. Thus, there is a reduction of $0.36 \%$ in total relay operating time using mixed characteristics as compared to EI characteristics. In addition, it can be seen that by using mixed characteristics the total relay operating time is reduced by $52.57 \%$ and $4.51 \%$ as compared to NI and VI characteristics, respectively. From the results, it can be concluded that by using optimally selected relay characteristics the total relay operating time is the least when compared to NI, VI, EI characteristics. Also only VI and EI characteristics are optimally selected in mixed characteristics. A graphical representation of the primary relay operating times obtained by GA with NI, VI, EI, and mixed characteristics in grid-connected mode using dual setting DOCR is shown in Fig. 5. The MCT and backup relay operating times for dual setting DOCR obtained by GA in grid-connected mode of the 7-bus microgrid system are presented in Figs. 6 and 7, respectively. Here $M C T$ can be defined as the actual operating time difference between the primary and backup relays using optimal values of TMS and PS. In all cases, the value of $M C T$ is always greater than $C T I$. This indicates the required time gap between primary and backup relays for each RP. The optimal results satisfy all the considered constraints while formulating the relay coordination problem. 
Table 3 Current through relay coils in grid-connected and islanded operating modes for 7-bus microgrid system

\begin{tabular}{|c|c|c|c|c|c|c|c|}
\hline \multirow[t]{3}{*}{ Faulty line } & \multirow[t]{3}{*}{ Relay pair } & \multirow[t]{3}{*}{ Primary relay } & \multirow{3}{*}{$\begin{array}{l}\text { Backup relay } \\
\text { (dual) }\end{array}$} & \multicolumn{4}{|c|}{ Fault current through relay coils } \\
\hline & & & & \multicolumn{2}{|c|}{ Grid-connected (A) } & \multicolumn{2}{|c|}{ Islanded mode (A) } \\
\hline & & & & Primary & Backup & Primary & Backup \\
\hline \multirow[t]{3}{*}{ L1 } & RP1 & R1 & R3 & 12.075 & 3.19 & 9.03 & 0.64 \\
\hline & $\mathrm{RP} 2$ & R1 & R5 & 12.075 & 2.53 & 9.03 & 1.76 \\
\hline & RP3 & R2 & R7 & 17.175 & 4.13 & 11.52 & 1.45 \\
\hline \multirow[t]{4}{*}{ L2 } & RP4 & R3 & $\mathrm{R} 1$ & 9.561 & 4.10 & 8.07 & 2.39 \\
\hline & RP5 & R3 & R5 & 9.561 & 2.16 & 8.07 & 1.04 \\
\hline & RP6 & R4 & $\mathrm{R} 14$ & 16.075 & 2.64 & 5.35 & 1.59 \\
\hline & RP7 & R4 & $\mathrm{R} 15$ & 16.075 & 1.69 & 5.35 & 3.30 \\
\hline \multirow[t]{3}{*}{ L3 } & RP8 & R5 & $\mathrm{R} 1$ & 17.196 & 3.27 & 12.4 & 2.32 \\
\hline & RP9 & R5 & R3 & 17.196 & 2.67 & 12.4 & 0.538 \\
\hline & RP10 & R6 & $\mathrm{R} 16$ & 16.785 & 6.18 & 11.72 & 2.60 \\
\hline \multirow[t]{2}{*}{ L4 } & RP11 & R7 & R2 & 7.038 & 9.94 & 6.174 & 7.34 \\
\hline & RP12 & R8 & R9 & 16.793 & 2.34 & 6.134 & 2.80 \\
\hline \multirow[t]{2}{*}{ L5 } & RP13 & R9 & $\mathrm{R} 8$ & 16.038 & 6.08 & 5.356 & 6.52 \\
\hline & RP14 & $\mathrm{R} 10$ & $\mathrm{R} 11$ & 11.634 & 10.86 & 8.65 & 7.85 \\
\hline \multirow[t]{2}{*}{ L6 } & RP15 & R11 & R10 & 19.90 & 19.37 & 9.154 & 8.36 \\
\hline & RP16 & $\mathrm{R} 12$ & $\mathrm{R} 13$ & 7.18 & 22.15 & 4.94 & 15.11 \\
\hline \multirow[t]{3}{*}{ L7 } & RP17 & $\mathrm{R} 13$ & $\mathrm{R} 12$ & 18.28 & 5.75 & 9.675 & 2.97 \\
\hline & RP18 & $\mathrm{R} 14$ & R4 & 11.04 & 5.51 & 6.43 & 6.37 \\
\hline & RP19 & R14 & R15 & 11.04 & 3.012 & 6.43 & 3.66 \\
\hline \multirow[t]{3}{*}{ L8 } & RP20 & R15 & R4 & 17.728 & 3.047 & 9.52 & 5.22 \\
\hline & RP21 & R15 & R14 & 17.728 & 2.075 & 9.52 & 1.435 \\
\hline & RP22 & R16 & R6 & 9.734 & 9.145 & 8.14 & 6.165 \\
\hline
\end{tabular}

\subsection{Optimum relay setting in islanded mode}

The optimal settings obtained by GA in islanded mode using dual setting DOCR, with NI, VI, EI and mixed relay characteristics are shown in Table 5. It is found that the total operating times of relays obtained by GA using NI and VI characteristics are $3.9882 \mathrm{~s}$ and $1.7765 \mathrm{~s}$, respectively. It can be seen that using VI characteristics, the total relay operating time obtained by GA can be minimized by $55.45 \%$ when compared to NI characteristics. Also, the operating time for relay R1 in RP1 is $0.2350 \mathrm{~s}$ for the forward direction whereas for the reverse direction of fault current the operating time of relay R1 in RP4 is $1.6779 \mathrm{~s}$ (with NI characteristics). Thus the relay operating time for the forward direction is lower than that of the reverse direction. Similarly, from the results obtained by GA using EI and mixed relay characteristics in islanded mode, the total dual setting DOCR operating times obtained by GA using EI and mixed characteristics are $1.6928 \mathrm{~s}$ and $1.6345 \mathrm{~s}$ respectively. By using mixed characteristics, the relay operating time obtained by GA is reduced by $59 \%$ and $7.99 \%$ compared to NI and VI characteristics, respectively. It can be concluded that by using optimally selected relay characteristics the relay operating time is lower than all the other (NI, VI, and EI) characteristics. In the islanded mode of operation, only VI and EI type relay characteristics are optimally selected in the case of mixed characteristics. The primary dual setting DOCR operating times obtained by GA using NI, VI, EI and mixed characteristics in islanded operating mode are shown in Fig. 8.

\subsection{Comparative analysis of results in dual operating mode}

The performance of dual setting DOCR in terms of the total relay operating time is compared with conventional DOCR [20], in Table 6. It can be seen that, as the relay characteristics change from NI to optimally selected mixed characteristics, there is a significant reduction in the relay operating time in both operating modes of the microgrid. To validate the effectiveness of 


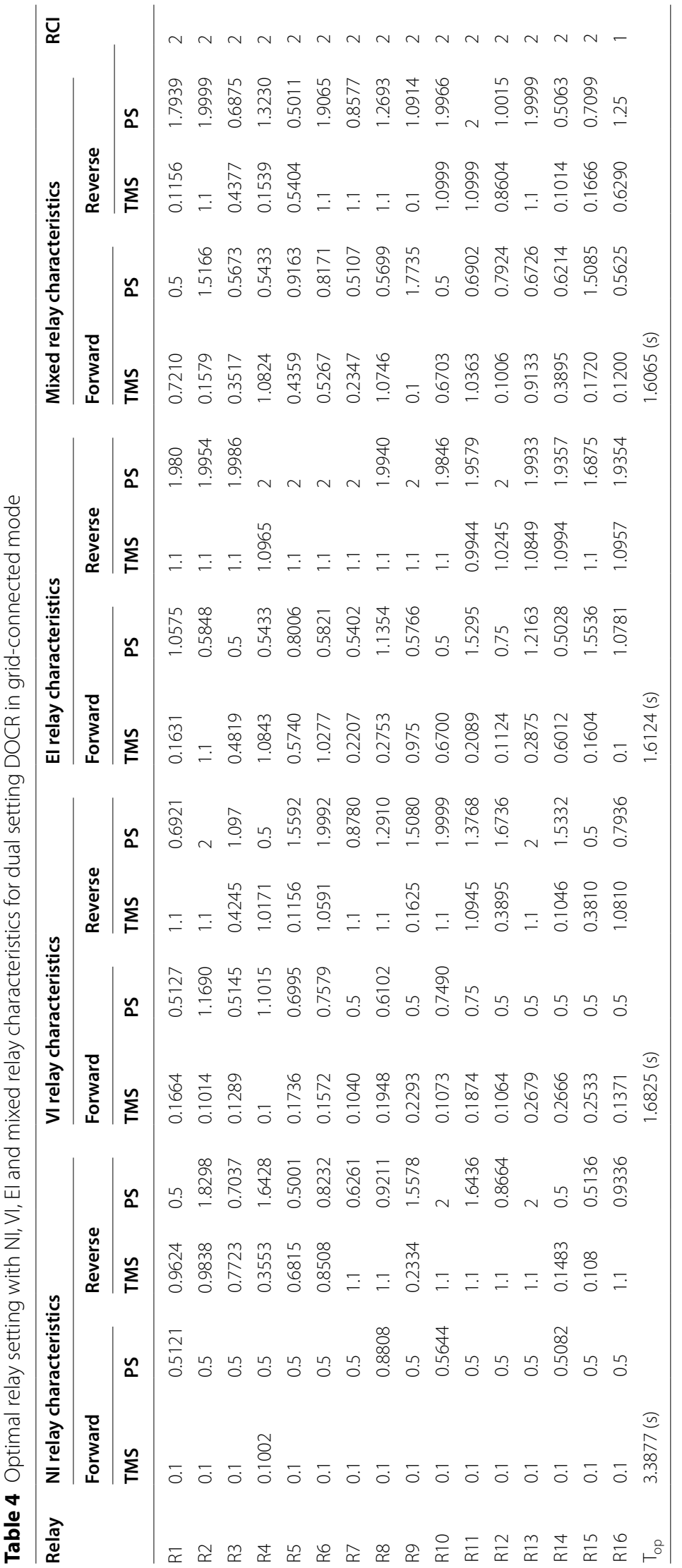




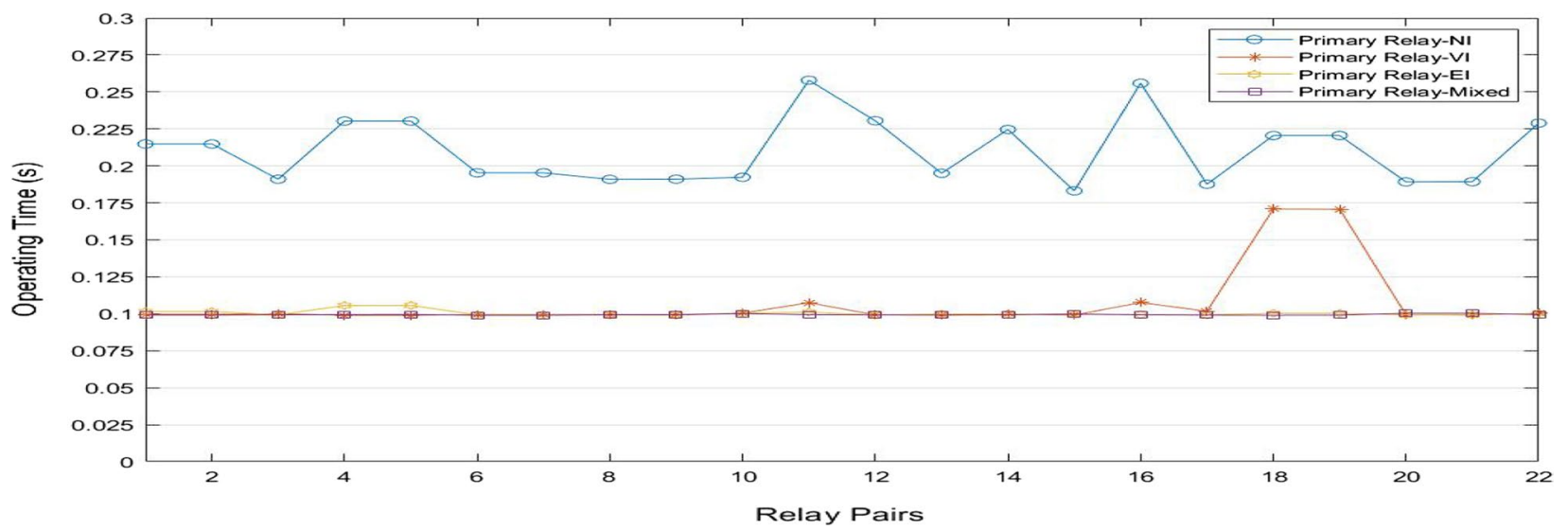

Fig. 5 Primary relay operating time having NI, VI, El and mixed characteristics in grid-connected mode

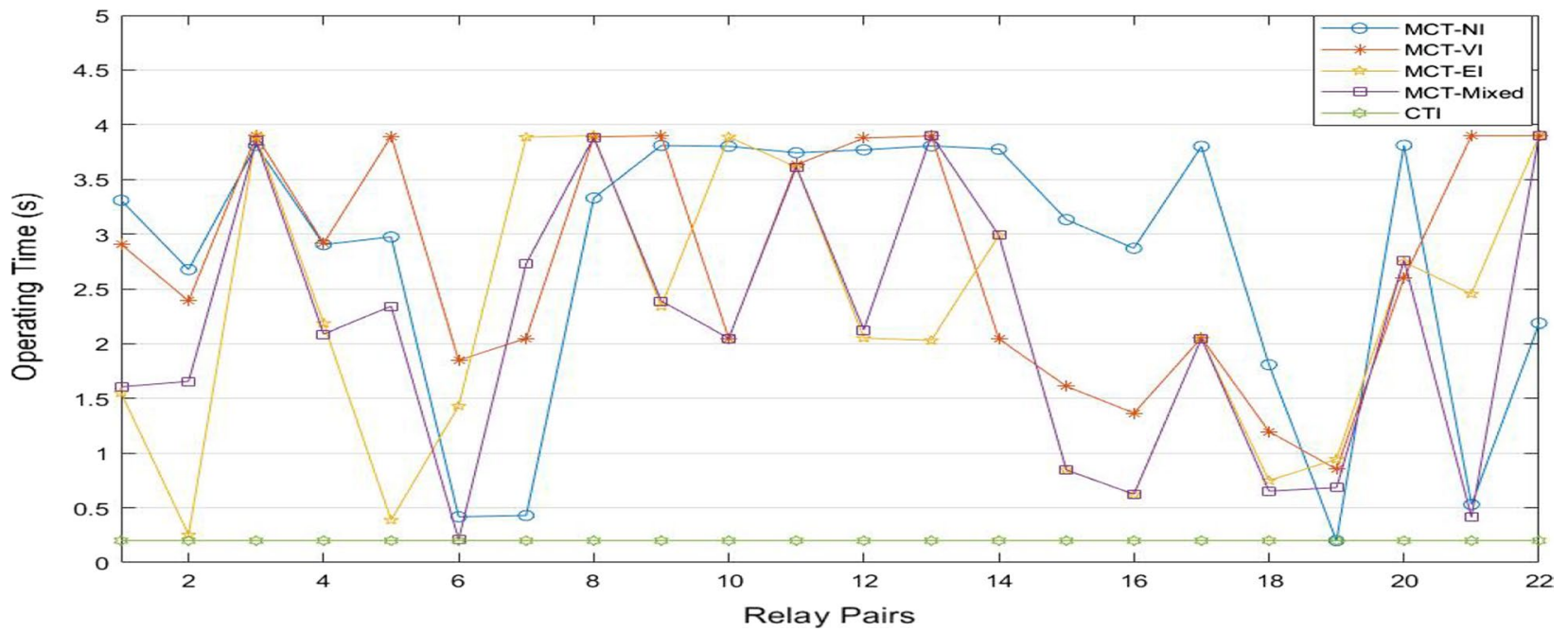

Fig. 6 MCT having NI, VI, and El and mixed characteristics using dual setting DOCR in grid-connected mode

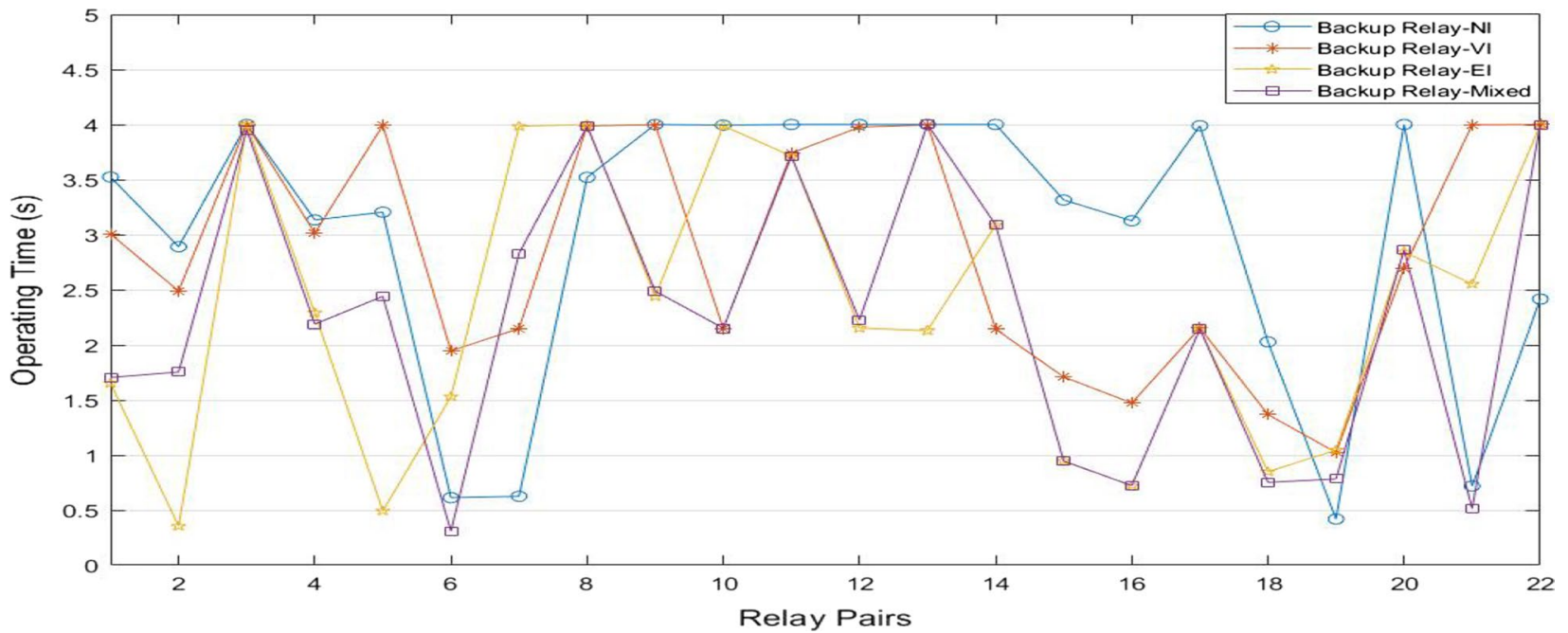

Fig. 7 Backup relay operating time having NI, VI, El and mixed characteristics in grid- connected mode 


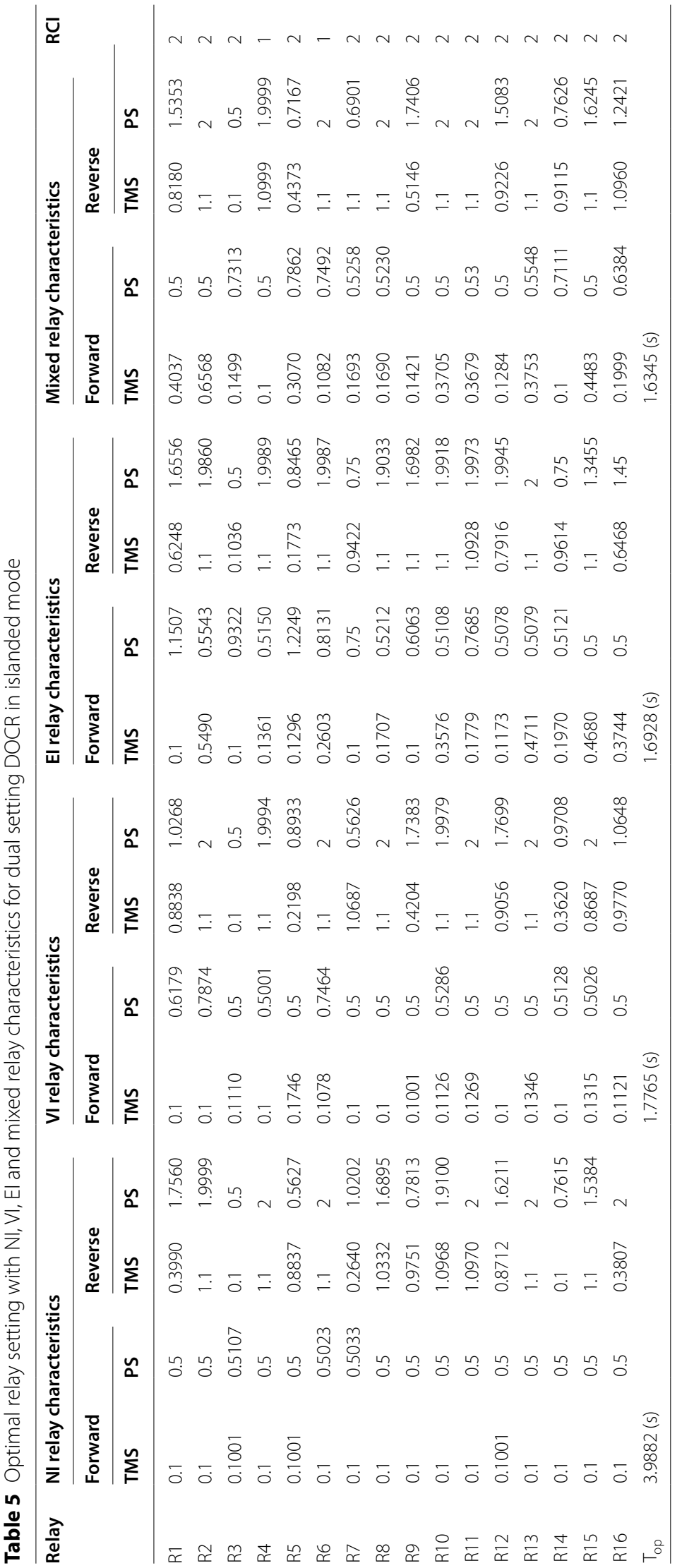




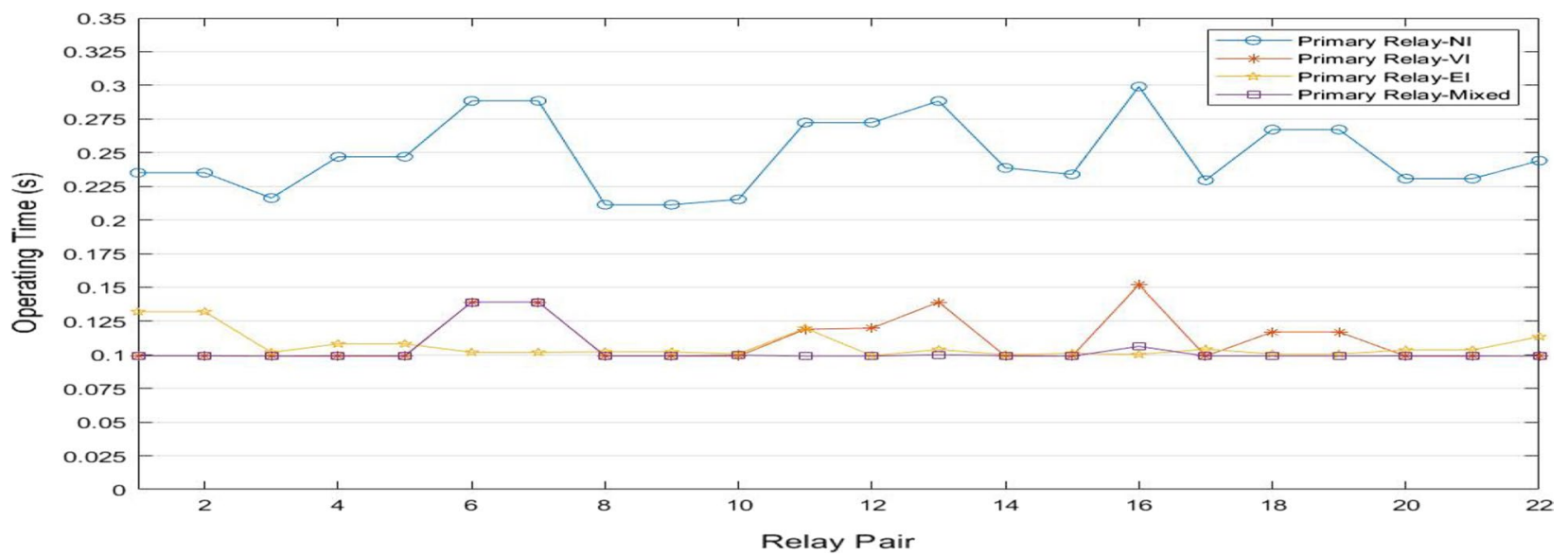

Fig. 8 Primary relay operating time having NI, VI, El and mixed characteristics in islanded mode

Table 6 Comparative analysis of conventional DOCR [20] and dual setting DOCR for 7-bus microgrid system

\begin{tabular}{|c|c|c|c|c|c|c|c|}
\hline $\begin{array}{l}\text { Operating } \\
\text { mode }\end{array}$ & $\begin{array}{l}\text { Relay } \\
\text { characteristics }\end{array}$ & $\begin{array}{l}\text { Conventional } \\
\text { DOCR operating } \\
\text { time (s) using } \\
\text { GA [20] }\end{array}$ & $\begin{array}{l}\text { Dual DOCR } \\
\text { operating time } \\
\text { (s) using GA }\end{array}$ & $\begin{array}{l}\text { Conventional } \\
\text { DOCR } \\
\text { operating time } \\
\text { (s) using GWO }\end{array}$ & $\begin{array}{l}\text { Dual DOCR } \\
\text { operating time } \\
\text { (s) using GWO }\end{array}$ & $\begin{array}{l}\text { Reduction } \\
\text { in total relay } \\
\text { operating time } \\
\text { using } \mathrm{GA}\end{array}$ & $\begin{array}{l}\text { Reduction } \\
\text { in total relay } \\
\text { operating time } \\
\text { using GWO }\end{array}$ \\
\hline \multirow[t]{4}{*}{ Grid-connected } & $\mathrm{NI}$ & 7.2041 & 3.3877 & 7.2453 & 3.4045 & $52.97 \%$ & $53.01 \%$ \\
\hline & $\mathrm{Vl}$ & 2.4392 & 1.6825 & 2.5482 & 1.7402 & $31.02 \%$ & $31.70 \%$ \\
\hline & El & 1.6681 & 1.6124 & 1.7053 & 1.6139 & $3.39 \%$ & $5.35 \%$ \\
\hline & Mixed & 1.6684 & 1.6065 & 1.6868 & 1.6103 & $3.71 \%$ & $4.53 \%$ \\
\hline \multirow[t]{4}{*}{ Islanded } & $\mathrm{NI}$ & 7.3148 & 3.9882 & 7.4868 & 3.9918 & $45.47 \%$ & $46.68 \%$ \\
\hline & $\mathrm{Vl}$ & 3.2457 & 1.7765 & 3.3625 & 1.7885 & $45.26 \%$ & $46.81 \%$ \\
\hline & $\mathrm{El}$ & 6.7142 & 1.6928 & 2.0911 & 1.7258 & $74.78 \%$ & 17.46 \\
\hline & Mixed & 2.0670 & 1.6345 & 2.0888 & 1.6459 & $20.92 \%$ & $21.20 \%$ \\
\hline
\end{tabular}

Table 7 Coordination constraint violation summary of the 7-bus microgrid system using GA

\begin{tabular}{|c|c|c|c|c|c|}
\hline \multirow[t]{2}{*}{ Setting calculated } & \multirow[t]{2}{*}{$\begin{array}{l}\text { Characteristics curve } \\
\text { considered }\end{array}$} & \multicolumn{2}{|c|}{$\begin{array}{l}\text { Constraint violation in conventional DOCR } \\
\text { [20] }\end{array}$} & \multicolumn{2}{|c|}{$\begin{array}{l}\text { Constraint violation in dual } \\
\text { setting DOCR }\end{array}$} \\
\hline & & Islanded & Grid-connected & Islanded & $\begin{array}{l}\text { Grid- } \\
\text { connected }\end{array}$ \\
\hline \multirow[t]{4}{*}{ Islanded } & $\mathrm{Nl}$ & $\mathrm{NIL}$ & 13 & NIL & 01 \\
\hline & $\mathrm{Vl}$ & NIL & 14 & NIL & 16 \\
\hline & El & NIL & 5 & NIL & 17 \\
\hline & Mixed & NIL & 12 & NIL & 16 \\
\hline \multirow[t]{4}{*}{ Grid-connected } & $\mathrm{NI}$ & 08 & NIL & 04 & NIL \\
\hline & $\mathrm{Vl}$ & 07 & NIL & 04 & NIL \\
\hline & El & 04 & $\mathrm{NIL}$ & 07 & NIL \\
\hline & Mixed & 06 & $\mathrm{NIL}$ & 05 & NIL \\
\hline
\end{tabular}




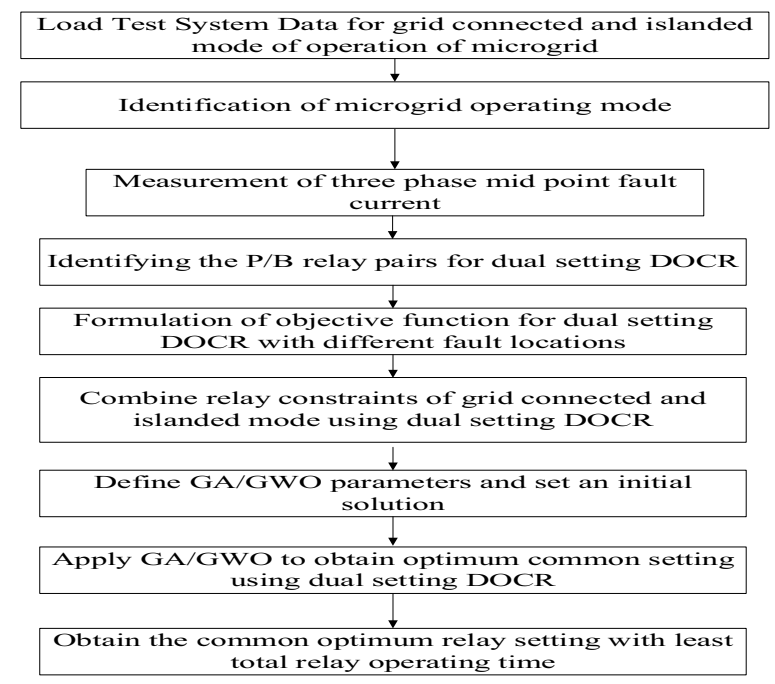

Fig. 9 Method for common optimal setting for dual operating modes of $M G$

GA, the results are also compared with the grey wolf optimization (GWO) technique. The results show that GA gives better results in terms of total relay operating time in all cases except the islanded case of conventional DOCR using EI characteristics. The percentage reduction in operating time of dual-setting DOCRs compared to conventional DOCR in each case is shown in Table 6. The violation constraints (in terms of number) in both operating modes of the microgrid are displayed in Table 7 , while any protection schemes are no longer valid if any of the constraints associated with the relay coordination problem are violated. It is seen that when the optimal settings obtained for grid-connected mode (for dual setting DOCRs) are applied in islanded mode, several constraints are violated ( 4 for NI, 4 for VI, 7 for EI and 5 for mixed characteristics). In the same way when the optimal relay settings of islanded mode are applied in grid-connected mode, some constraints are violated ( 1 for NI, 16 for VI, 17 for EI and 16 for mixed characteristics). Therefore, it is desirable to obtain a common relay setting for the operation of the protection scheme, one which can satisfy all the operating mode constraints.

\subsection{Common optimum relay setting in dual operating modes of microgrid}

The proposed method for a common optimal setting that can be used in both operating modes is shown in Fig. 9, where the effects of both operating modes of the microgrid are taken into account, to identify the common optimal relay setting for dual setting DOCRs. In this process, all the relay constraints of both operating modes are considered together when minimizing the objective function. The common optimal relay settings obtained by GA with the optimally selected relay characteristics are shown in Table 8 . The primary relay operating times obtained by GA using conventional and dual setting overcurrent relays are displayed in Fig. 10. In this case, the number of relays remains the same, but the number of relay constraint, and relay pairs, are doubled (RP1-RP44) compared to grid-connected or islanded operating mode (RP1-RP22). The results reveal that for the obtained common relay settings, all three types of relay characteristics, i.e., NI, VI, and EI, are optimally determined. The total relay operating times obtained by GA are found to be $1.6800 \mathrm{~s}$ for dual setting DOCR and $2.4392 \mathrm{~s}$ for conventional DOCR [20]. This represents a reduction of $31.12 \%$ while using dual setting relays with the common optimal settings, while the constraints in both operating modes are completely satisfied, i.e., no constraint violation occurs for either of the operating modes.

\section{Proposed protection scheme validation on 18-bus microgrid system}

To validate the effectiveness of the proposed protection scheme, the proposed protection method implemented on the distribution part of the IEEE-14 bus test system is applied in a similar manner to a larger microgrid system, i.e., the distribution part of the IEEE-30 bus test system (an 18-bus microgrid system) is considered. The 18-bus microgrid system consists of 22 lines, one SG (50MVA) connected at bus B1, and three IBDG (20 MVA each) at buses B4, B11, and B18 [20]. The other relevant information regarding the IEEE-30 bus system is given in "Appendix". To protect this system, 44 dual setting relays (R1-R44) are required. These are placed at both ends of the lines as shown in Fig. 11. The system is connected to the utility grid through buses B1, B2 and B16 as shown in Fig. 11 . The primary-backup relay pairs (RP1-RP72) for different fault locations (L1-L22) are shown in Table 9. In this test system, for some of the relay pairs, the fault currents flowing through the respective backup relays are very small compared to the primary relays because the backup relay operating times are larger than those of the primary relays. Such relay pairs are ignored during the relay coordination process, as they always satisfy the respective constraints. All other test system information is taken from [22]. To show 
Table 8 Common optimal relay setting using dual setting DOCR for 7-bus microgrid system

\begin{tabular}{|c|c|c|c|c|c|c|c|c|c|c|c|}
\hline \multirow[t]{2}{*}{ Relay } & \multicolumn{2}{|c|}{ Forward } & \multicolumn{2}{|c|}{ Reverse } & \multirow[t]{2}{*}{$\mathrm{RCl}$} & \multirow[t]{2}{*}{ Relay } & \multicolumn{2}{|c|}{ Forward } & \multicolumn{2}{|c|}{ Reverse } & \multirow[t]{2}{*}{$\mathrm{RCl}$} \\
\hline & TMS & PS & TMS & PS & & & TMS & PS & TMS & PS & \\
\hline R1 & 0.5071 & 0.595 & 0.1000 & 0.816 & 2 & R9 & 0.2205 & 0.516 & 0.610 & 0.500 & 1 \\
\hline R2 & 0.6757 & 0.734 & 0.9420 & 1.649 & 2 & $\mathrm{R} 10$ & 0.6688 & 0.500 & 1.1000 & 1.744 & 2 \\
\hline R3 & 0.1329 & 0.500 & 0.1188 & 0.500 & 1 & R11 & 0.2159 & 1.502 & 1.1000 & 1.638 & 2 \\
\hline R4 & 0.1000 & 0.500 & 0.3501 & 1.657 & 3 & $\mathrm{R} 12$ & 0.2540 & 0.500 & 1.0990 & 0.531 & 2 \\
\hline R5 & 0.7841 & 0.682 & 0.1626 & 0.504 & 2 & $\mathrm{R} 13$ & 0.1614 & 1.594 & 1.1000 & 2.000 & 2 \\
\hline R6 & 0.1000 & 1.146 & 0.9213 & 1.500 & 1 & R14 & 0.6022 & 0.500 & 0.1000 & 0.572 & 2 \\
\hline R7 & 0.2440 & 0.500 & 0.1610 & 0.622 & 2 & R15 & 0.1000 & 1.211 & 0.2417 & 0.500 & 1 \\
\hline R8 & 0.2390 & 0.5000 & 1.1000 & 1.2920 & 1 & $\mathrm{R} 16$ & 0.1333 & 0.5075 & 0.1475 & 0.8044 & 1 \\
\hline Top & $1.68(\mathrm{~s})$ & & & & & & & & & & \\
\hline
\end{tabular}

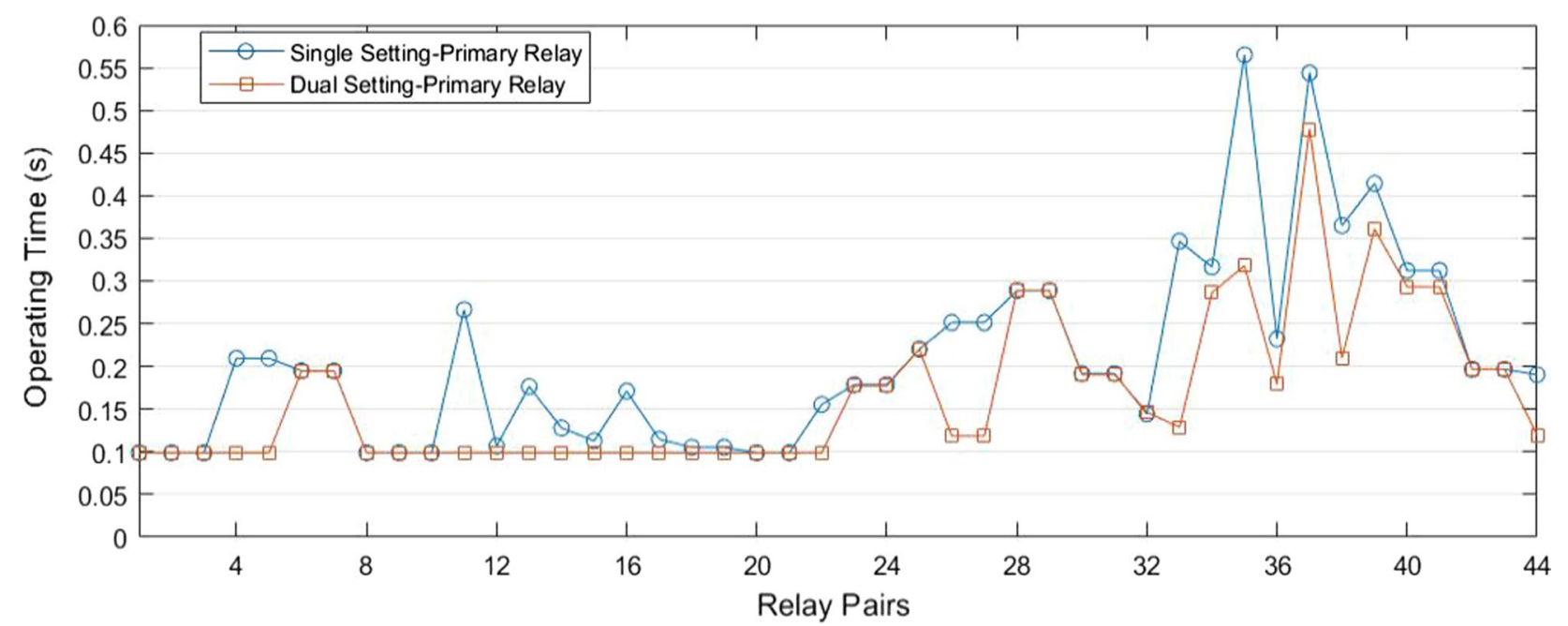

Fig. 10 Primary relay operating time using single and dual setting DOCR for common relay setting

the efficacy of the proposed protection scheme for the 18-bus microgrid system, only the common operating mode is considered due to page limitations. To determine the common optimal relay settings which can be used in both operating modes, the impacts of both operating modes are considered simultaneously. Therefore, the number of constraints is doubled compared to those in the individual operating mode. The minimum and maximum values of TMS, PS, and primary relay operating time are considered the same as in the 7-bus microgrid system. The common optimal relay settings for the 18-bus microgrid system using dual-setting overcurrent relays, obtained by GA are shown in Table 10. From Table 10, it can be seen that the total primary relay operating time obtained by GA for dual setting overcurrent relays, is $4.4472 \mathrm{~s}$, which is $60.47 \%$ lower than that for conventional DOCRs [20] as shown in Table 11. The primary relay operating times for all the relay pairs (RP1-RP144) associated with grid-connected mode (RP1-RP72) and islanded mode (RP73-RP144) using single and dual setting overcurrent relays in common operating mode are shown in Fig. 12.

It can be concluded that the common optimal relay settings satisfy all the constraints related to grid-connected and islanded mode of operation simultaneously. Thus, 


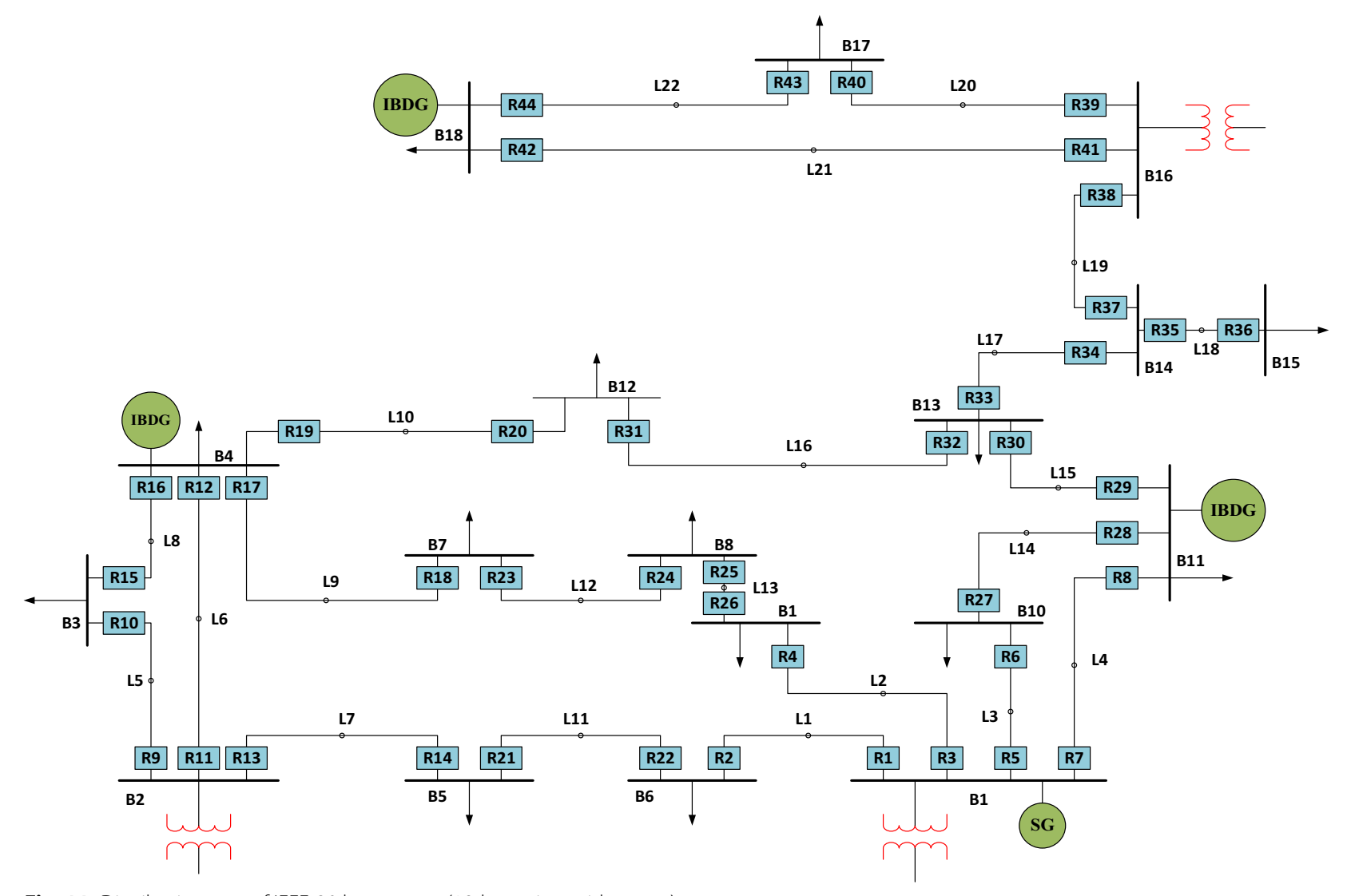

Fig. 11 Distribution part of IEEE-30 bus system (18-bus microgrid system)

the proposed protection scheme using dual-setting overcurrent relays also provides the common optimal relay settings for larger test system such as the 18-bus microgrid test system which can be used in both operating modes. To show the efficacy of the GA, a comparative analysis in terms of total relay operating time for both test systems (the 7-bus and 18-bus microgrid systems) is shown in Table 11. It can be seen there that the total relay operating times obtained by the GA are better than the GWO for both test cases. In addition, the total primary relay operating time in the common operating mode using dual setting DOCR is always lower than the conventional DOCR [20].

\section{Conclusion}

This paper presents a comparative analysis of relay coordination for 7-bus and 18-bus microgrid systems using dual-setting relays in both operating modes of a microgrid. One of the major findings of the research is the determination of common settings of dual setting relays for both operating modes of the microgrid. From the results, it can be concluded that the relay operating times in both modes decrease significantly as the relay characteristics change. In this context, for the 7-bus microgrid system, 16 dual-setting relays (R1-R16) have been considered with NI, VI, EI and mixed characteristics by which the total relay operating times are reduced by $52.97 \%, 31.02 \%, 3.39 \%$ and $3.71 \%$ in grid-connected mode, and by $45.47 \%, 45.26 \%$, $74.78 \%$ and $20.92 \%$ in islanded mode as compared to conventional DOCR. Also, in common operating mode, the percentage reductions in total relay operating time for dual setting DOCR obtained by GA in the 7 -bus and 18-bus microgrid systems are $31.02 \%$ and $60.47 \%$ respectively, compared to the conventional DOCR. Similarly, the percentage reductions in total relay operating time for dual-setting DOCR obtained by GWO in the 7-bus and 18-bus microgrid systems 


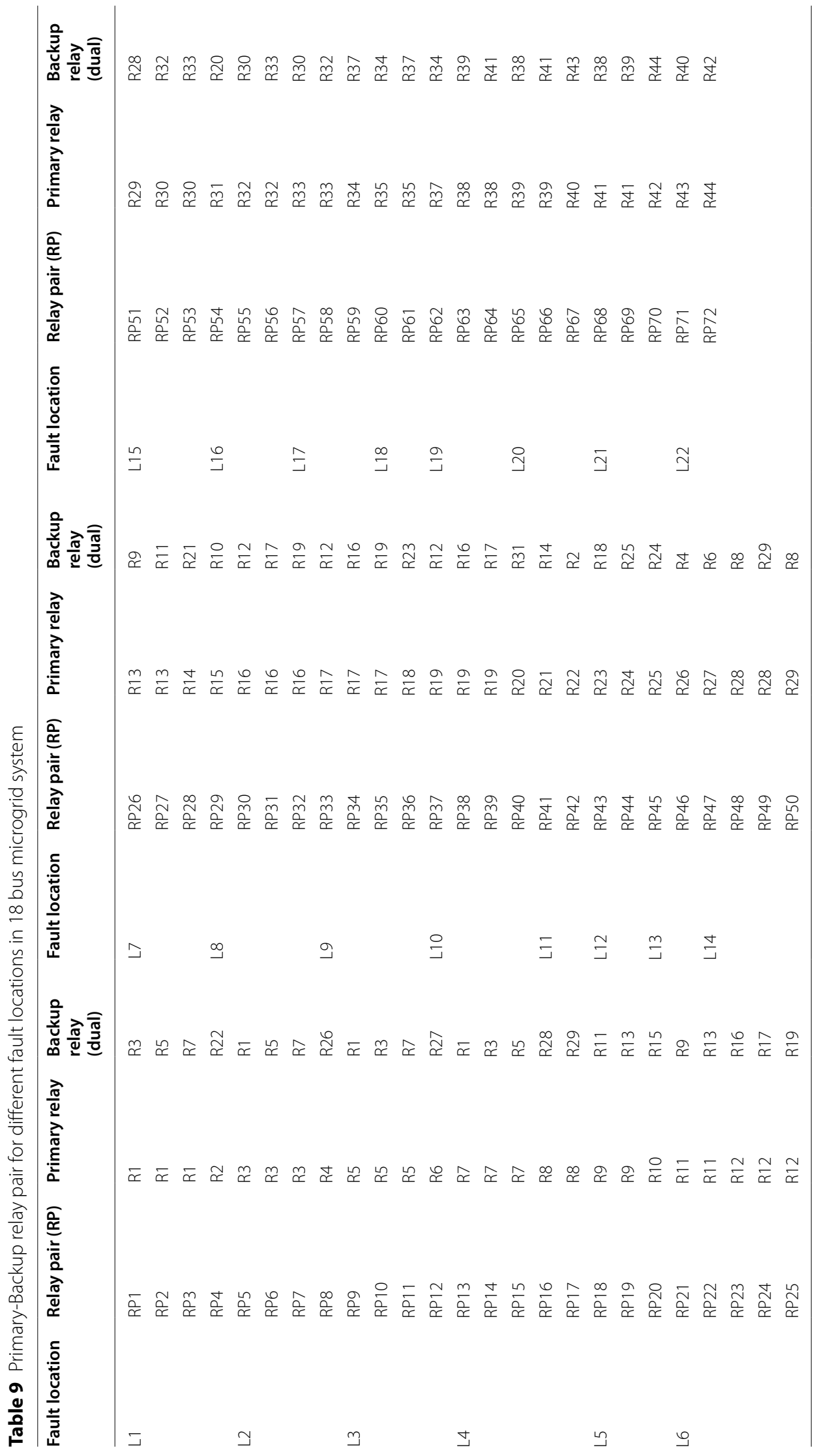


Table 10 Optimal relay setting for common operating mode in 18 bus microgrid system using GA

\begin{tabular}{|c|c|c|c|c|c|c|c|c|c|c|c|}
\hline \multirow[t]{2}{*}{ Relay } & \multirow[t]{2}{*}{$\mathrm{RCl}$} & \multicolumn{2}{|c|}{ Forward } & \multicolumn{2}{|c|}{ Reverse } & \multirow[t]{2}{*}{ Relay } & \multirow[t]{2}{*}{$\mathrm{RCl}$} & \multicolumn{2}{|c|}{ Forward } & \multicolumn{2}{|c|}{ Reverse } \\
\hline & & TMS & PS & TMS & PS & & & TMS & PS & TMS & PS \\
\hline 1 & 2 & 0.2909 & 1.1371 & 1.1000 & 1.9998 & 23 & 1 & 0.2277 & 0.5167 & 1.1000 & 1.9998 \\
\hline 2 & 2 & 0.1 & 1.7002 & 0.4104 & 0.5510 & 24 & 2 & 0.4351 & 0.9222 & 1.1000 & 1.0659 \\
\hline 3 & 2 & 0.1477 & 1.7122 & 1.1000 & 2.0000 & 25 & 2 & 0.1581 & 1.5164 & 1.1000 & 0.6721 \\
\hline 4 & 2 & 1.0844 & 0.5740 & 0.7170 & 0.5913 & 26 & 2 & 0.5009 & 0.6876 & 1.1000 & 2.0000 \\
\hline 5 & 2 & 0.8237 & 0.7349 & 1.1000 & 2.0000 & 27 & 2 & 0.4578 & 0.9954 & 1.0751 & 1.9645 \\
\hline 6 & 1 & 0.2503 & 0.5144 & 1.0034 & 0.7500 & 28 & 2 & 0.1000 & 1.9102 & 1.1000 & 2.0000 \\
\hline 7 & 2 & 0.6753 & 0.7578 & 1.1000 & 2.0000 & 29 & 2 & 0.5285 & 0.7757 & 1.1000 & 1.9953 \\
\hline 8 & 2 & 0.2382 & 1.1168 & 1.1000 & 1.6350 & 30 & 2 & 0.4732 & 0.8708 & 1.0933 & 1.9979 \\
\hline 9 & 2 & 0.5338 & 0.8283 & 1.1000 & 2.0000 & 31 & 2 & 0.4841 & 0.9310 & 0.9246 & 1.4508 \\
\hline 10 & 2 & 1.0805 & 0.5953 & 1.1000 & 0.5156 & 32 & 2 & 0.1660 & 1.5015 & 1.1000 & 2.0000 \\
\hline 11 & 1 & 0.2643 & 0.5162 & 1.1000 & 1.1119 & 33 & 2 & 0.7823 & 0.7869 & 1.1000 & 2.0000 \\
\hline 12 & 2 & 0.2656 & 1.3253 & 1.1000 & 2.0000 & 34 & 2 & 1.0812 & 0.5786 & 1.1000 & 1.9987 \\
\hline 13 & 2 & 1.0956 & 0.6344 & 1.1000 & 1.8827 & 35 & 2 & 0.3466 & 1.0587 & 1.1000 & 1.2698 \\
\hline 14 & 2 & 0.8333 & 0.6044 & 1.1000 & 2.0000 & 36 & 2 & 0.2712 & 0.5864 & 1.1000 & 0.7618 \\
\hline 15 & 2 & 0.3386 & 1.1727 & 0.1061 & 0.5050 & 37 & 2 & 0.2140 & 1.5094 & 0.1841 & 1.3251 \\
\hline 16 & 2 & 1.0961 & 0.5312 & 1.1000 & 2.0000 & 38 & 1 & 0.2141 & 0.5218 & 1.1000 & 1.9983 \\
\hline 17 & 2 & 0.1610 & 1.5053 & 1.1000 & 2.0000 & 39 & 2 & 0.3391 & 1.1641 & 1.1000 & 2.0000 \\
\hline 18 & 2 & 1.0198 & 0.6835 & 1.1000 & 1.9844 & 40 & 2 & 1.0323 & 0.6713 & 1.1000 & 2.0000 \\
\hline 19 & 2 & 0.3944 & 0.9916 & 1.1000 & 1.9985 & 41 & 2 & 1.0477 & 0.6434 & 1.1000 & 1.9999 \\
\hline 20 & 2 & 0.9609 & 0.5456 & 1.0377 & 1.3120 & 42 & 3 & 0.1001 & 0.5000 & 1.1000 & 2.0000 \\
\hline 21 & 2 & 0.5839 & 0.7671 & 1.0999 & 2.0000 & 43 & 2 & 1.0830 & 0.5672 & 1.1000 & 0.8326 \\
\hline 22 & 2 & 0.2362 & 1.2411 & 1.1000 & 2.0000 & 44 & 2 & 0.9623 & 0.6789 & 1.1000 & 2.0000 \\
\hline$T_{o p}$ & $4.4472(\mathrm{~s})$ & & & & & & & & & & \\
\hline
\end{tabular}

Table 11 Summary of total relay operating time using single and dual setting overcurrent relays in common operating mode

\begin{tabular}{llllll}
\hline Sr. nos & Test system & $\begin{array}{l}\text { Optimization } \\
\text { technique }\end{array}$ & \multicolumn{2}{l}{ Total relay operating time (s) } & \multicolumn{2}{c}{$\begin{array}{l}\text { Percentage reduction in } \\
\text { total relay operating time }\end{array}$} \\
\cline { 5 - 6 } & & Conventional DOCR & Dual setting DOCR & $31.12 \%$ \\
\hline 1 & 7 Bus microgrid & GA [20] & 2.4392 & 1.6800 & $30.24 \%$ \\
& & GWO & 2.4412 & 1.7028 & $60.47 \%$ \\
& 18 Bus microgrid & GA [20] & 11.2509 & 4.4472 & $34.96 \%$ \\
\hline
\end{tabular}

are $30.24 \%$ and $34.96 \%$ respectively when compared to conventional DOCR. One of the major advantages of the proposed technique is that there is no constraints violation in either operating mode of the microgrid.
The performance of the proposed protection scheme can be further enhanced by taking the relay characteristic coefficients ( $\alpha$ and $\beta$ ) as continuous variables. 


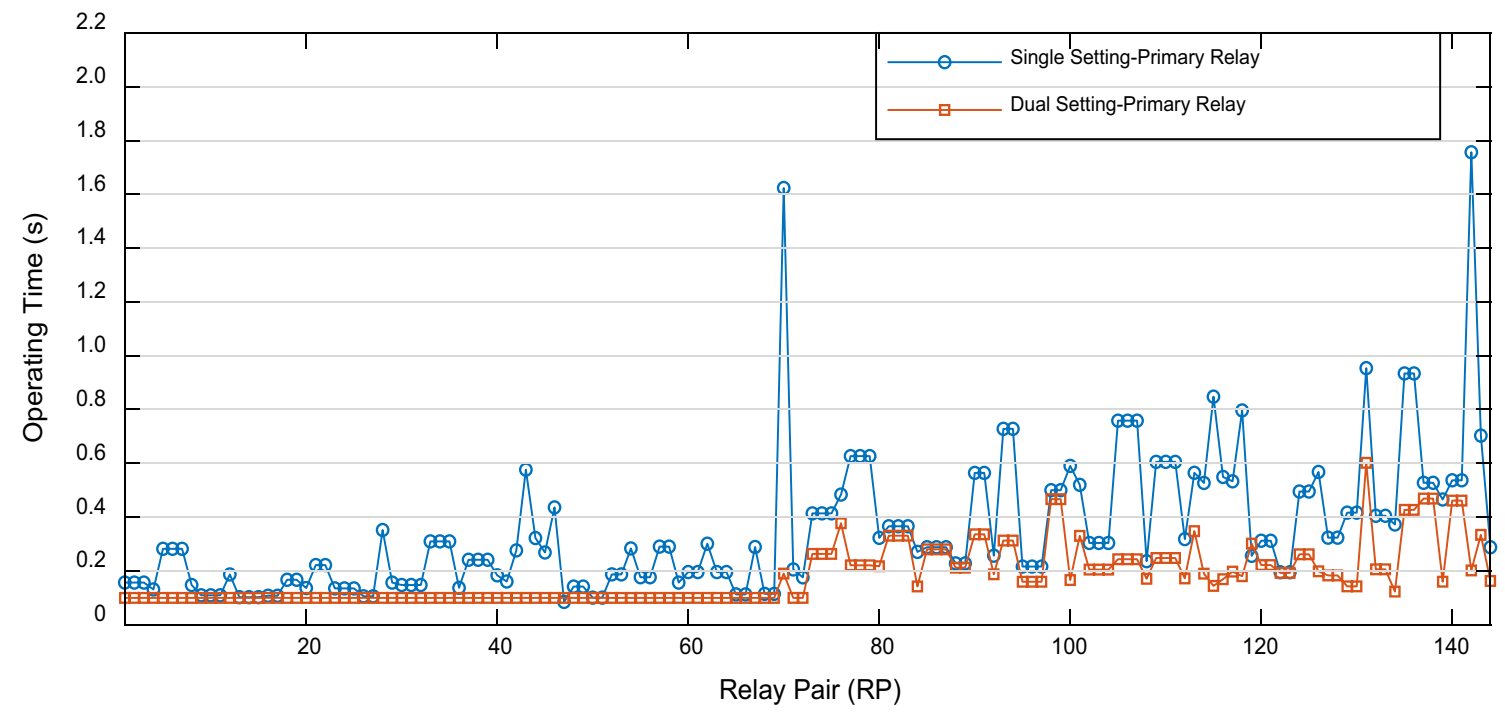

Fig.12 Primary relay operating time using single and dual setting overcurrent relays for common relay setting in 18 bus microgrid test system

\section{Appendix}

See Tables 12, 13 and 14.

Table 12 Bus load and injection data of IEEE 30-bus system

\begin{tabular}{lrlr}
\hline Bus & Load & Bus & Load \\
\hline 1 & 0.0 & 16 & 3.5 \\
2 & 21.7 & 17 & 9.0 \\
3 & 2.4 & 18 & 3.2 \\
4 & 67.6 & 19 & 9.5 \\
5 & 34.2 & 20 & 2.2 \\
6 & 0.0 & 21 & 17.5 \\
7 & 22.8 & 22 & 0.0 \\
8 & 30.0 & 23 & 3.2 \\
9 & 0.0 & 24 & 8.7 \\
10 & 5.8 & 25 & 0.0 \\
11 & 0.0 & 26 & 3.5 \\
12 & 11.2 & 27 & 0.0 \\
13 & 0.0 & 28 & 0.0 \\
14 & 6.2 & 29 & 2.4 \\
15 & 8.2 & 30 & 10.6 \\
\hline
\end{tabular}

Table 13 Reactive power limit of IEEE-30 bus test system

\begin{tabular}{llllll}
\hline Bus & Qmin (p.u.) & Qmax (p.u.) & Bus & Qmin (p.u.) & Qmax (p.u.) \\
\hline 1 & -0.2 & 0.0 & 16 & & \\
2 & -0.2 & 0.2 & 17 & -0.05 & 0.05 \\
3 & & & 18 & 0.0 & 0.055 \\
4 & & & 19 & & \\
5 & -0.15 & 0.15 & 20 & & \\
6 & & & 21 & & \\
7 & & & 22 & & \\
8 & -0.15 & 0.15 & 23 & -0.05 & 0.055 \\
9 & & & 24 & & \\
10 & & & 25 & & \\
11 & -0.1 & 0.1 & 26 & & \\
12 & & & 27 & -0.055 & 0.055 \\
13 & -0.15 & 0.15 & 28 & & \\
14 & & & 29 & & \\
15 & & & 30 & & \\
\hline
\end{tabular}


Table 14 Line parameter of IEEE-30 bus test system

\begin{tabular}{|c|c|c|c|c|c|c|}
\hline Line & From bus & To bus & /t (p.u.) & $I$ (p.u) & Tap ratio & Rating (p.u) \\
\hline 1 & 1 & 2 & 0.0192 & 0.0575 & & 0.300 \\
\hline 2 & 1 & 3 & 0.0452 & 0.1832 & 0.9610 & 0.300 \\
\hline 3 & 2 & 4 & 0.0570 & 0.1737 & 0.9560 & 0.300 \\
\hline 4 & 3 & 4 & 0.0132 & 0.0379 & & 0.300 \\
\hline 5 & 2 & 5 & 0.0472 & 0.1983 & & 0.300 \\
\hline 6 & 2 & 6 & 0.0581 & 0.1763 & & 0.300 \\
\hline 7 & 4 & 6 & 0.0119 & 0.0414 & & 0.300 \\
\hline 8 & 5 & 7 & 0.0460 & 0.1160 & & 0.300 \\
\hline 9 & 6 & 7 & 0.0267 & 0.0820 & & 0.300 \\
\hline 10 & 6 & 8 & 0.0120 & 0.0420 & & 0.300 \\
\hline 11 & 6 & 9 & 0.0000 & 0.2080 & & 0.300 \\
\hline 12 & 6 & 10 & 0.0000 & 0.5560 & & 0.300 \\
\hline 13 & 9 & 11 & 0.0000 & 0.2080 & & 0.300 \\
\hline 14 & 9 & 10 & 0.0000 & 0.1100 & 0.9700 & 0.300 \\
\hline 15 & 4 & 12 & 0.0000 & 0.2560 & 0.9650 & 0.650 \\
\hline 16 & 12 & 13 & 0.0000 & 0.1400 & 0.9635 & 0.650 \\
\hline 17 & 12 & 14 & 0.1231 & 0.2559 & & 0.320 \\
\hline 18 & 12 & 15 & 0.0662 & 0.1304 & & 0.320 \\
\hline 19 & 12 & 16 & 0.0945 & 0.1987 & & 0.320 \\
\hline 20 & 14 & 15 & 0.2210 & 0.1997 & & 0.160 \\
\hline 21 & 16 & 17 & 0.0824 & 0.1932 & & 0.160 \\
\hline 22 & 15 & 18 & 0.1070 & 0.2185 & & 0.160 \\
\hline 23 & 18 & 19 & 0.0639 & 0.1292 & 0.9590 & 0.160 \\
\hline 24 & 19 & 20 & 0.0340 & 0.0680 & & 0.320 \\
\hline 25 & 10 & 20 & 0.0936 & 0.2090 & & 0.320 \\
\hline 26 & 10 & 17 & 0.0324 & 0.0845 & 0.9850 & 0.320 \\
\hline 27 & 10 & 21 & 0.0348 & 0.0749 & & 0.300 \\
\hline 28 & 10 & 22 & 0.0727 & 0.1499 & & 0.300 \\
\hline 29 & 21 & 22 & 0.0116 & 0.0236 & & 0.300 \\
\hline 30 & 15 & 23 & 0.1000 & 0.2020 & & 0.160 \\
\hline 31 & 22 & 24 & 0.1150 & 0.1790 & & 0.300 \\
\hline 32 & 23 & 24 & 0.1320 & 0.2700 & 0.9655 & 0.160 \\
\hline 33 & 24 & 25 & 0.1885 & 0.3292 & & 0.300 \\
\hline 34 & 25 & 26 & 0.2544 & 0.3800 & & 0.300 \\
\hline 35 & 25 & 27 & 0.1093 & 0.2087 & & 0.300 \\
\hline 36 & 28 & 27 & 0.0000 & 0.3960 & & 0.300 \\
\hline 37 & 27 & 29 & 0.2198 & 0.4153 & 0.9810 & 0.300 \\
\hline 38 & 27 & 30 & 0.3202 & 0.6027 & & 0.300 \\
\hline 39 & 29 & 30 & 0.2399 & 0.4533 & & 0.300 \\
\hline 40 & 8 & 28 & 0.0636 & 0.2000 & 0.9530 & 0.300 \\
\hline 41 & 6 & 28 & 0.0169 & 0.0599 & & 0.300 \\
\hline
\end{tabular}

\section{Abbreviations}

DOCR: Directional overcurrent relay; TMS: Time multiplier setting; PS: Plug setting; RCl: Relay characteristics identifier; CTI: Coordination time interval; CTR: Current transformer ratio; RP: Relay pair; OF: Objective function; NI: Normal inverse; Vl: Very inverse; El: Extremely inverse; IIDG: Inverter interface distributed generator; SBDG: Synchronous based distributed generator; CCM: Current control mode; VCM: Voltage control mode; GA:: Genetic algorithm; GWO: Grey wolf optimization.
Acknowledgements

Not applicable.

\section{Authors' contributions}

RT carried out problem formulation, simulation, calculations, preparing manuscript, RKS and NKC participated in problem conceptualization, coordination and helped to draft manuscript. All authors read and approved the final manuscript. 


\begin{abstract}
Authors' information
Mr. Raghvendra Tiwari is Research Scholar pursuing his PhD in Electrical Engg. from Motilal Nehru National Institute of Technology (MNNIT) Allahabad, Prayagraj (U.P), India., he graduated (2007) and post graduated (2013) in Electrical Engg. From National Institute of Technical Teachers Training and Research (NITTTR), Chandigarh (Haryana). His areas of interest include Power system analysis, power system protection and artificial intelligence.

Prof. Ravindra Kumar Singh is presently working as a Professor (H.A.G) in Dept of Electrical Engg., MNNIT Allahabad, Prayagraj (U.P.) India. He has completed his PhD from IIT, Kanpur. His areas of interest include Power electronics, power system protection, and power systems.

Dr. Niraj Kumar Choudhary is presently working as a Asst. Professor in Dept of Electrical Engg., MNNIT Allahabad, Prayagraj (U.P.) India. He has completed his PhD from MNNIT Allahabad. His areas of interest include renewable energy and distributed generation based power system power system protection, and microgrid protection and smart grid, integration issues of DG in distribution system.
\end{abstract}

\section{Funding}

No funding received from any agency.

\section{Availability of data and materials}

Not applicable.

\section{Declarations}

\section{Competing interests}

The authors declare that they have no known competing financial interests or personal relationships that could have appeared to influence the work reported in this paper.

Received: 21 September 2020 Accepted: 27 January 2022 Published online: 21 February 2022

\section{References}

1. Singh, M. (2017). Protection coordination in distribution systems with and without distributed energy resources - A review. Protection and Control of Modern Power Systems, 2, 27. https://doi.org/10.1186/s41601-017-0061-1

2. Alam, M. N., Das, B., \& Pant, V. (2016). An interior point method based protection coordination scheme for directional overcurrent relays in meshed networks. International Journal of Electrical Power and Energy Systems. https://doi.org/10.1016/j.ijepes.2016.02.012

3. Wadood, A., Farkoush, S. G., Khurshaid, T., Kim, C. H., Jiangtao, Y., Geem, Z. W., \& Rhee, S. B. (2018). An optimized protection coordination scheme for the optimal coordination of overcurrent relays using a nature-inspired root tree algorithm. Applied Sciences (Switzerland). https://doi.org/10. 3390/app8091664

4. Khurshaid, T., Wadood, A., Farkoush, S. G., Kim, C. H., Jiangtao, Yu., \& Rhee, S. B. (2019). Improved firefly algorithm for the optimal coordination of directional overcurrent relays. IEEE Access, 7, 78503-78514. https://doi. org/10.1109/ACCESS.2019.2922426

5. Bedekar, P. P., Bhide, S. R., \& Kale, V. S. (2009). Optimum coordination of overcurrent relays in distribution system using genetic algorithm. In 2009 International conference on power systems, ICPS '09 (pp. 1-6). https://doi. org/10.1109/ICPWS.2009.5442716.

6. Barzegari, M., Bathaee, S. M.T., \& Alizadeh, M. (2010). Optimal coordination of directional overcurrent relays using harmony search algorithm. In 2010 9th Conference on environment and electrical engineering, EEEIC 2010 (Vol. 7, pp. 321-24). https://doi.org/10.1109/EEEIC.2010.5489935.

7. Tjahjono, A., Anggriawan, D. O., Faizin, A. K., Priyadi, A., Pujiantara, M., Taufik, T., \& Purnomo, M. H. (2017). Adaptive modified firefly algorithm for optimal coordination of overcurrent relays. IET Generation, Transmission and Distribution, 11(10), 2575-2585. https://doi.org/10.1049/iet-gtd.2016.1563

8. Sharma, A., Kiran, D., \& Panigrahi, B. K. (2018). Planning the coordination of overcurrent relays for distribution systems considering network reconfiguration and load restoration. IET Generation, Transmission and Distribution, 12(7), 1672-1679. https://doi.org/10.1049/iet-gtd.2017.1674

9. Srivastava, A., Tripathi, J. M., Krishan, R., \& Parida, S. K. (2018). Optimal coordination of overcurrent relays using gravitational search algorithm with DG penetration. IEEE Transactions on Industry Applications, 54(2), 1155-1165. https://doi.org/10.1109/TIA.2017.2773018

10. Birla, D., Maheshwari, R. P., Gupta, H. O., Deep, K., \& Thakur, M. (2006) Application of random search technique in directional overcurrent relay coordination. International Journal of Emerging Electric Power Systems, 7(1), 1-16. https://doi.org/10.2202/1553-779X.1271

11. Singh, M., Panigrahi, B. K., \& Abhyankar, A. R. (2013). Optimal coordination of directional over-current relays using teaching learning-based optimization (TLBO) algorithm. International Journal of Electrical Power and Energy Systems, 50(1), 33-41. https://doi.org/10.1016/j.ijepes.2013.02.011

12. Radosavljević, J., \& Jevtić, M. (2016). Hybrid GSA-SQP algorithm for optimal coordination of directional overcurrent relays. IET Generation, Transmission and Distribution, 10(8), 1928-1937. https://doi.org/10.1049/ iet-gtd.2015.1223

13. Costa, M. H., Saldanha, R. R., Ravetti, M. G., \& Carrano, E. G. (2017). Robust coordination of directional overcurrent relays using a matheuristic algorithm. IET Generation, Transmission and Distribution, 11(2), 464-474. https://doi.org/10.1049/iet-gtd.2016.1010

14. Albasri, F. A., Alroomi, A. R., \& Talaq, J. H. (2015). Optimal coordination of directional overcurrent relays using biogeography-based optimization algorithms. IEEE Transactions on Power Delivery, 30(4), 1810-1820. https:// doi.org/10.1109/TPWRD.2015.2406114

15. Solati Alkaran, D., Vatani, M. R., Sanjari, M. J., Gharehpetian, G. B., \& Naderi, M. S. (2018). Optimal overcurrent relay coordination in interconnected networks by using fuzzy-based GA method. IEEE Transactions on Smart Grid, 9(4), 3091-3101. https://doi.org/10.1109/TSG.2016.2626393

16. Sharaf, H. M., Zeineldin, H. H., Ibrahim, D. K., El Din, E., \& El-Zahab, A. (2015). A proposed coordination strategy for meshed distribution systems with DG considering user-defined characteristics of directional inverse time overcurrent relays. International Journal of Electrical Power and Energy Systems, 65, 49-58. https://doi.org/10.1016/j.ijepes.2014.09.028

17. Sharaf, H. M., Zeineldin, H. H., \& El-Saadany, E. (2018). Protection coordination for microgrids with grid-connected and islanded capabilities using communication assisted dual setting directional overcurrent relays. IEEE Transactions on Smart Grid, 9(1), 143-151. https://doi.org/10.1109/TSG.2016.2546961

18. Nimpitiwan, N., Heydt, G. T., Ayyanar, R., \& Suryanarayanan, S. (2007). Fault current contribution from synchronous machine and inverter based distributed generators. IEEE Transactions on Power Delivery, 22(1), 634-641. https://doi.org/10.1109/TPWRD.2006.881440

19. Khademi, M. M. (2017). Designing a coordinated protection system for microgrids enabled with DERs based on unidirectional FCL. CIRED - Open Access Proceedings Journal, 2017(1), 1027-1030. https://doi.org/10.1049/ oap-cired.2017.0192

20. Najy, W. K. A., Zeineldin, H. H., \& Woon, W. L. (2013). Optimal protection coordination for microgrids with grid-connected and islanded capability. IEEE Transactions on Industrial Electronics, 60(4), 1668-1677. https://doi. org/10.1109/TIE.2012.2192893

21. Alam, M. N. (2019). Overcurrent protection of AC microgrids using mixed characteristic curves of relays. Computers and Electrical Engineering, 74, 74-88. https://doi.org/10.1016/j.compeleceng.2019.01.003

22. Christie R. Power system test cases. (1993). www.ee.washington.edu/ research/pstca.

\section{Submit your manuscript to a SpringerOpen ${ }^{\circ}$ journal and benefit from:}

- Convenient online submission

- Rigorous peer review

- Open access: articles freely available online

- High visibility within the field

Retaining the copyright to your article

Submit your next manuscript at $\mathbf{s p r i n g e r o p e n . c o m ~}$ 